\title{
Corneal thickness and endothelial density before and after cataract surgery
}

\author{
A C Sobottka Ventura, R Wälti, M Böhnke
}

\begin{abstract}
Backgroundlaims-Deturgescence of the corneal stroma is controlled by the pumping action of the endothelial layer and can be monitored by measurement of central corneal thickness (pachymetry). Loss or damage of endothelial cells leads to an increase in corneal thickness, which may ultimately induce corneal decompensation and loss of vision. Little is known about the effect of moderate reductions in endothelial cell number on the thickness of the corneal stroma. This study aimed to investigate this matter further using patients who had incurred moderate decreases in their endothelial cell counts as a result of cataract surgery.

Methods-Central corneal thickness was measured 1 day before surgery, 1 day after surgery, and again at 3 months or 1 year. Endothelial cell counts were also performed 1 day before surgery and thereafter at 3 months or 1 year after surgery. The relationship between these two parameters was assessed statistically. Precise measurements of central corneal thickness were made by optical low coherence reflectometry. For comparative purposes, this parameter was also determined by ultrasonic pachymetry. Central corneal endothelial cell numerical density was estimated on photomicrographs taken with a specular microscope.
\end{abstract}

Results-All patients had significant postoperative corneal swelling on the day after surgery; preoperative values were restored by 3 and 12 months, even though significant endothelial cell losses had occurred. No correlation existed between central corneal thickness and central corneal endothelial cell numerical density. Measurements estimated by ultrasonic pachymetry were more variable and significantly higher than those determined by optical low coherence reflectometry. Conclusion-As long as the numerical density of the corneal endothelial cells does not fall below the physiological threshold, a moderate decrease in this parameter does not compromise the pumping activity of the layer as a whole. (Br f Ophthalmol 2001;85:18-20)

Endothelial cells of the human cornea maintain this tissue in a dehydrated state by their pumping activity, thereby assuring its transparency, This is an active process which is controlled by $\mathrm{Na}^{+} / \mathrm{K}^{+}$-ATPase and involves the generation of a bicarbonate ion gradient across the corneal endothelium. ${ }^{1-5}$

The corneal endothelium consists of a monolayer of polygonal cells, the numerical density of which is highest at birth $\left(3000 \text { cells } / \mathrm{mm}^{2}\right)^{6}$ and declines slowly but steadily thereafter. ${ }^{78} \mathrm{~A}$ minimal numerical density of $400-500$ cells/ $\mathrm{mm}^{2}$ is required to sustain the pumping activity of the endothelium. Dysfunction results in corneal decompensation and loss of vision. The fact that the endothelium becomes gradually depleted of cells rather than compensating for its losses reflects the limited capacity of these cells to regenerate. ${ }^{610}$ This situation may become exacerbated by losses incurred during the course of certain diseases or after intraocular surgery. ${ }^{78}$

The corneal thickness of newborn infants is highest during the first 24 hours after birth and decreases significantly after 48 hours. ${ }^{11}{ }^{12}$ This thinning process continues steadily until the age of $3,{ }^{13}$ at which time the thickness of the adult cornea is attained. ${ }^{14}$ Thereafter there is a gradual but insignificant decrease in the thickness of this tissue. ${ }^{15-20}$ The rate of corneal deswelling after oedema, measured as the percentage recovery per hour, is significantly higher in young patients than in older ones. ${ }^{21} 22$

Moderate damage of the corneal endothelium during surgery may lead to a transient increase in corneal thickness as measured by pachymetry, although data pertaining to this are contradictory. Some authors have reported that all patients regained preoperative values after 4 weeks, ${ }^{23}{ }^{24}$ whereas others have found increases to be sustained up to 6 months $\mathrm{s}^{25}{ }^{26}$ or even 1 year postoperatively. ${ }^{27}$ These discrepancies may reflect inexactitudes both in the measurement of central corneal thickness (by ultrasonic pachymetry) and in the estimation of endothelial cell numerical density. In the former instance, incorrect placement of the pachymeter head and the relative experience of the operator may be sources of considerable variation.

It has now become possible to make more precise measurements of the central corneal thickness by optical low coherence reflectometry. This study was undertaken to ascertain whether a moderate decrease in endothelial cell numerical density induced by a single phacoemulsification step influences the central corneal thickness, accurately determined, in a given individual at various time intervals up to 1 year after surgery.

Patients and methods

PATIENTS

Thirty white patients (15 women and 15 men) of mean (SD) age 71 (15) years (range 34-93) were examined at a single ophthalmology unit 


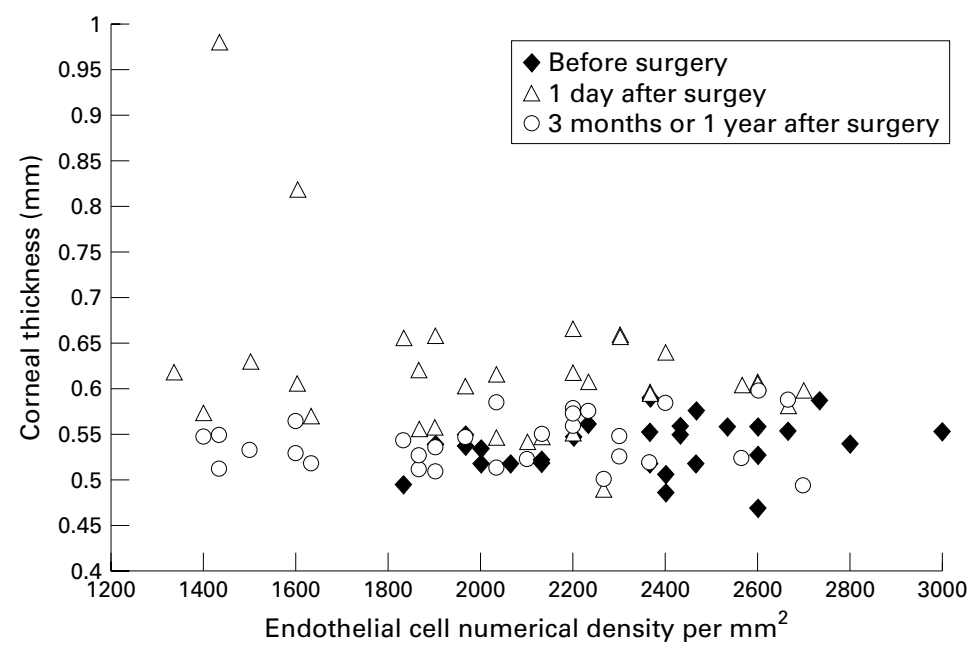

Figure 1 Corneal thickness and endothelial cell numerical density measured by optical low coherence reflectometry 1 day before surgery, 1 day after surgery, and 3 or 12 months after surgery.

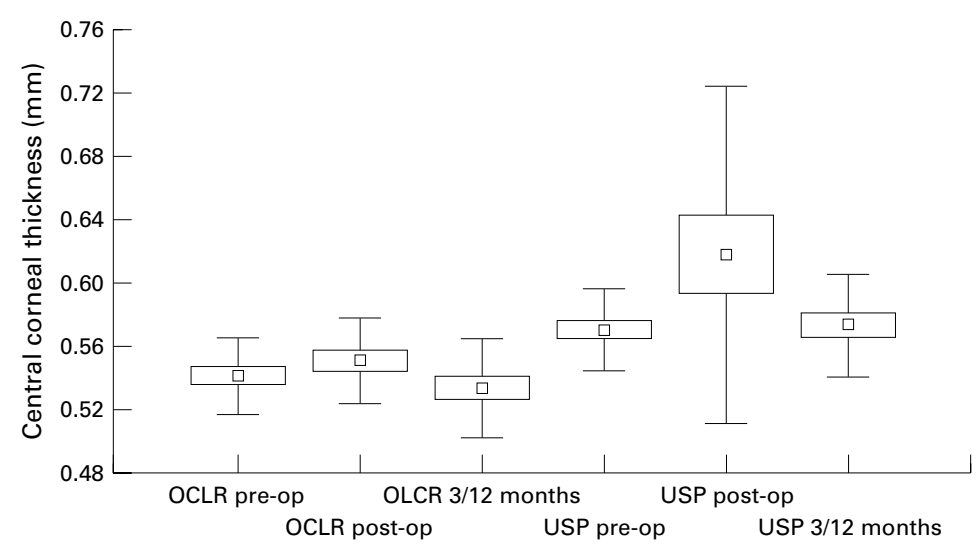

Figure 2 Central corneal thickness measured by optical low coherence reflectometry (OLCR) and ultrasonic pachymetry (USP) 1 day before surgery (pre-op), 1 day after surgery (post-op), and 3 or 12 months after surgery.

(Inselspital, University of Bern, Switzerland) between January 1998 and September 1999. All patients were informed as to the nature of the study and consented to undergo corneal thickness and endothelial cell numerical density measurements.

STUDY DESIGN

All patients underwent cataract surgery performed by the same surgeon (phacoemulsification and implantation of an intraocular lens). Measurements of the central corneal thickness were made 1 day before, 1 day after, and then again at 3 months or 1 year after the operation (according to when the subject was available for examination).

Central corneal thickness was measured with an optical low coherence reflectometer operating at a scanning speed of $0.5 \mathrm{~m} / \mathrm{s}$ and a repetition rate of $15 \mathrm{~Hz}$ using a superluminescent diode (emission wavelength $850 \mathrm{~nm}$ ). For each eye $(n=32)$ the mean (SD) value of 60 consecutive scans was calculated, all measurements being made by the same person. This method has a precision of about $1 \mu \mathrm{m}$ and a high intrasession and intersession reproducibility. ${ }^{28-31}$

For comparative purposes the central corneal thickness was also measured by ultrasonic pachymetry (DGH 1000 Technology Inc). For each eye the mean (SD) value of three measurements, each determined by the same person, was calculated. According to the manufacturer the precision of this method is about $5-10 \mu \mathrm{m}$.

The numerical density of endothelial cells in the central cornea (cells $/ \mathrm{mm}^{2}$ ) was estimated on photomicrographs taken with a non-contact specular microscope SP1000 (Topcon Corporation, Fisba Optik, St Gallen, Switzerland) using the fixed frame technique. For each eye the mean of measurements made on three micrographs was calculated. The inexactitude of this method lies in the range of $5-10 \%$.

Statistical analyses were performed using the Student's $t$ test and Wilcoxon's test.

\section{Results}

Before surgery the mean (SD) central corneal thickness of the patient cohort was 537 (27) $\mu \mathrm{m}$ (range 469-590 $\mu \mathrm{m}$; Figs 1 and 2). One day after surgery all corneas had a significantly increased central corneal thickness compared with the preoperative values $(\mathrm{p}=0.002$; mean 621 (95) $\mu \mathrm{m}$; range 488-980 $\mu \mathrm{m}$; Figs 1 and 2) and with those made on fellow eyes 1 day after surgery $(p<0.001$ (data not shown)). After 3 months or 1 year the corneal thickness had returned to preoperative values $(\mathrm{p}=0.004$; mean 539 (28) $\mu \mathrm{m}$; range 494-597 $\mu \mathrm{m}$; Figs 1 and 2). Fellow eyes exhibited slight but insignificant thinning at this second postoperative examination (data not shown).

All patients incurred significant endothelial cell losses after surgery, the mean loss being 346 (94) cells $/ \mathrm{mm}^{2}(16 \% ; \mathrm{p}=0.001 ;$ Fig 1$)$.

Ultrasonic pachymetric estimates of central corneal thickness were, on average, $0.036 \mu \mathrm{m}$ greater (range $0.031-0.040 \mu \mathrm{m} ; \mathrm{n}=100$ ) than those determined by optical low coherence reflectometry, this difference being significant $(p \leqslant 0.048)$.

There was no correlation between central corneal thickness and central corneal endothelial cell numerical density.

\section{Discussion}

The results of this study confirm the findings of other authors that endothelial cell numerical density within the physiological range is not correlated with central corneal thickness. ${ }^{23-27}$ Our data further reveal that central corneal thickness returns to preoperative values after 3 or 12 months, irrespective of the severity of endothelial cell loss. This finding supports the data published by Cheng et $a l^{23}$ and Amon et al. ${ }^{24}$ The persistent increases in central corneal thickness reported by Olsen ${ }^{25}{ }^{26}$ and Kohlhaas et $a l^{27} 6$ and 12 months, respectively, after surgery could have been due to the imprecision of the ultrasonic pachymetric measurements (3-65 $\mu \mathrm{m}$ deviation from true values) ${ }^{32}$ or to pre-existing abnormalities in endothelial cell morphology. ${ }^{33}$

Reported measurements of central corneal thickness determined by ultrasonic pachymetry exhibited greater fluctuations than did those estimated by optical low coherence reflectometry. Apart from this, differences in mean values for a particular individual at a 
given time were also observed between the two methods of measurement. This discrepancy has its origin in the calibration of the ultrasonic pachymeter and arises from errors of amplification for the refractive index and/or the speed of ultrasound in the cornea.

Kohlhaas et $a l^{27}$ reported no further postoperative loss of endothelial cells after 4 weeks, which suggests that wound healing is complete by this time. This postulate accords well with the findings of Cheng et $a l^{23}$ and Amon et $a l^{4}$ who also observed preoperative corneal thickness values to be restored within a similar period of time.

A healthy cornea is able to compensate rapidly for transient increases in central corneal thickness after cataract surgery, but such is not the case when the endothelium is diseased. In patients with endothelial polymegathism the return to preoperative values of corneal thickness is significantly slower than in those with a normal endothelium. ${ }^{33}$ Furthermore, a positive correlation has been found between central corneal thickness, corneal permeability, and endothelial cell size in patients with cornea guttata. ${ }^{34}$ It is also of interest that, in studies with explanted corneal buttons derived from patients with bullous keratopathy, a linear regression for corneal thickness and the number of keratocytes has been observed..$^{35}$ In individuals with a predamaged endothelium, postoperative corneal swelling has been shown to be greater after 4 days and even 6 months than in those with a healthy endothelium. ${ }^{16}$ Furthermore, in patients who have undergone cataract surgery or who are suffering from Fuchs' disease, the deswelling rate of the cornea is significantly lower than in controls. ${ }^{36}$

Large diurnal fluctuations in corneal thickness are observed in most individuals, ${ }^{37}$ but these may be accentuated after anterior segment surgery. ${ }^{38}$

Precise measurements of corneal thickness may therefore serve as a parameter for assessing overall endothelial function in corneas with a diseased endothelium or with borderline low endothelial cell counts. In corneas which have incurred moderate reductions in the number of otherwise healthy endothelial cells, the corneal thickness does not increase. A healthy endothelium is thus able to maintain corneal dehydration over a large range of endothelial cell counts. In order to evaluate the degree of surgical trauma and endothelial status, morphological criteria are more precise. This is because the functional capacity of the endothelium is substantial and corneal cell depletion is not reflected in corneal thickness measurements until there has been substantial loss of corneal endothelial cells.

1 Hodson S. Evidence for a bicarbonate-dependent sodium pump in corneal endothelium. Exp Eye Res 1971;11:20-9. 2 Maurice DM. The location of the fluid pump in the cornea. f Physiol 1972;221:43-54

3 Dikstein S, Maurice DM. The metabolic basis of the fluid pumps in the cornea. F Physiol 221:29-41.

4 Fischbarg J, Lim JJ. Role of cations, anions and carbonic anhydrase in fluid transport across rabbit corneal endotheanhydrase in fluid transport acros
lium. f Physiol 1974;241:647-75.
5 Geroski HH, Matsuda M, Yee RW, et al. Pump function of the human corneal endothelium. Effects of age and cornea the human corneal endothelium. Effect

guttata. Ophthalmology 1985;92:759-63.
6 Waring GO, Bourne WM, Edelhauser HF, et al. The corneal Waring GO, Bourne WM, Edelhauser HF, et al. The corneal tion. Ophthalmology 1982;89:531-90.

7 Bourne WM, Kaufman HE. Specular microscopy of human corneal endothelium in vivo. Am f Ophthalmol 1976;81: 319-26.

8 Bourne WM, O'Fallon WM. Endothelial cell loss during penetrating keratoplasty. Am f Ophthalmol 1978;85:760-6.

9 Kaufman HE, Capella JA, Robbins JE. The human corneal endothelium. Am f Ophthalmol 1966;61:835-41.

10 Capella JA. Regeneration of endothelium in diseased and injured corneas. Am $\mathcal{f}$ Ophthalmol 1972;74:810-7.

11 Portellinha W, Belfort R Jr. Central and peripheral corneal thickness in newborns. Acta Ophthalmol 1991;69:247-50.

12 Remon L, Cristobal J, Castillo J, et al. Central and peripheral corneal thickness in full-term newborns by ultrasonic pachymetry. Invest Ophthalmol Vis Sci 1992;33: 3080-3.

13 Autzen T, Bjornstrom L. Central corneal thickness in premature babies. Acta Ophthalmol 1991;69:251-2.

14 Ehlers N, Sorensen T, Bramsen T, et al. Central corneal thickness in newborns and children. Acta Ophthalmol 1976;54:285-90.

15 Korey M, Gieser D, Kass MA, et al. Central corneal endothelial cell density and central corneal thickness in ocular hypertension and primary open-angle glaucoma. Am $\mathcal{F}$ Ophthalmol 1982;94:610-6.

16 Olsen T. Light scattering from the human cornea. Invest Ophthalmol Vis Sci 1982;23:81-6.

17 Rapuano CJ, Fishbaugh JA, Strike DJ. Nine point corneal thickness measurements and keratometry readings in normal corneas using ultrasound pachymetry. Insight 1993; 18: 16-22.

18 Herse P, Yao W. Variation of corneal thickness with age in young New Zealanders. Acta Ophthalmol 1993;71:360-4.

$19 \mathrm{Li} \mathrm{JH}$, Zhou F, Zhou SA. Research on corneal thickness at multi-points in normal and myopic eyes. Chung Hua Yen Ko Tsa Chih 1994;30:445-8.

20 Lam AK, Douthwaite WA. The corneal-thickness profile in Hong Kong Chinese. Cornea 1998;17:384-8.

21 Polse KA, Brand R, Mandell R, et al. Age differences in corneal hydration control. Invest Ophthalmol Vis Sci 1989;30: 392-9.

22 Siu A, Herse P. The effect of age on human corneal thickness. Statistical implications of power analysis. Acta Ophthalmol 1993;71:51-6.

23 Cheng H, Bates AK, Wood L, et al. Positive correlation of corneal thickness and endothelial cell loss. Arch Ophthalmol 1988;106:920-2

24 Amon M, Menapace R, Radax U, et al. Endothelial cell density and corneal pachometry after no-stitch, small-incision cataract surgery. Doc Ophthalmol 1992;81:301-7.

25 Olsen T. Corneal thickness and endothelial damage after intracapsular cataract extraction. Acta Ophthalmol 1980;58: $424-33$

26 Olsen T, Eriksen JS. Corneal thickness and endothelial damage after intraocular lens implantation. Acta Ophthalmol 1980;58:773-86.

27 Kohlhaas M, Stahlhut O, Tholuck J, et al. Changes in corneal thickness and endothelial cell density after cataract extraction using phacoemulsification. Ophthalmologe 1997. 94:515-8.

28 Böhnke M, Chavanne P, Gianotti R, et al. High precision, high speed measurement of eximer laser keratectomies with a new optical pachymeter. Ger f Ophthalmol 1997;5:338-42.

29 Wälti Gianotti R, Bonvin P, Ballif JJ, et al. Rapid and precise in vivo measurement of human corneal thickness with optiin vivo measurement of human corneal thickness with optical low-coherence reflectome

F Biomed Optics 1998;3:253-8.
30 Böhnke M, Masters BR, Wälti R, et al. Precision and reproducibility of measurements of human corneal thickness with rapid optical low-coherence reflectometry (OLCR). f Biomed Optics 1999;4:152-6.

31 Masters BR. Early development of optical low-coherence reflectometry and some recent biomedical applications. f Biomed Optics 1999;4:236-47.

32 Wheeler NC, Morantes CM, Kristensen RM, et al. Reliability coefficients of three corneal pachymeters. Am $\mathcal{F}$ Ophthalmol 1992;113:645-51.

33 Rao GN, Shaw EL, Arthur EJ, et al. Endothelial cell morphology and corneal deturgescence. Ann Ophthalmol 1979;11:885-99.

34 Burns RR, Bourne WM, Brubaker RF. Endothelial function in patients with cornea guttata. Invest Ophthalmol Vis Sci 1981;20:77-85.

35 Liu GJ, Okisaka S, Mizukawa A, et al. Histopathological study of pseudophakic bullous keratopathy developing after anterior chamber of iris-supported intraocular lens implantation. Fpn F Ophthalmol 1993;37:414-25.

36 Saini JS, Mittal S. In vivo quantification of corneal endothelium function. Acta Ophthalmol Scand 1996;74:468-72.

37 Harper CL, Boulton ME, Bennett D, et al. Diurnal variations in human corneal thickness. $\mathrm{Br} f$ Ophthalmol 1996;80:1068-72.

38 Hara T, Hara T. Postoperative change in the corneal thickness of the pseudophakic eye: amplified diurnal variation and consensual increase. 7 Cataract Refract Surg 1987;13:325-9. 